\title{
Urban air pollution reduction: evidence from phase-wise analysis of COVID-19 pandemic lockdown
}

\author{
Shailendra Kumar Yadav ${ }^{1} \cdot$ Raghav Sharma $^{1} \cdot$ Sankalp Kumar ${ }^{1} \cdot$ Aviral Agarwal $^{1} \cdot$ Vignesh Mohan $^{1}$. \\ Rajeev Kumar Mishra ${ }^{1} \cdot$ Ankita Shukla $^{2}$
}

Received: 21 February 2021 / Accepted: 26 June 2021 / Published online: 16 July 2021

(C) Saudi Society for Geosciences 2021

\begin{abstract}
Until 31 May 2020, more than six million confirm COVID-19 cases had been reported worldwide. Lockdown has resulted in significant air quality improvement, especially in urban regions. The lockdown has acted as a natural experiment empowering researchers, policymakers, and governing bodies. The present study focuses on quantifying and analysing the effect of lockdown on India's metropolitan cities, namely New Delhi, Mumbai, Kolkata, Chennai, and Bangalore. The study analyses the phase-wise and diurnal variations in the air quality from 24 March 2020 to 31 May 2020 while focussing on-peak and off-peak duration concentrations. To investigate the reason behind pollutant reduction, correlation of drop percentages in pollutant concentrations with vehicle population, extent of construction activity, and meteorological parameters are analysed. The 24-h drop in $\mathrm{PM}_{10}$ and $\mathrm{PM}_{2.5}$ showed a high correlation $\left(R^{2}=0.97\right.$ and 0.72 , respectively) with the city's vehicle population. During peak hours, the inland cities (Delhi and Bangalore), with a more extensive vehicle fleet, recorded a higher drop in $\mathrm{PM}_{10}$ and $\mathrm{PM}_{2.5}$ concentrations than coastal cities (Mumbai, Chennai, and Kolkata). With respect to 2019 concentration, the maximum decrease in pollutant concentrations averaged across the five study locations was recorded in $\mathrm{NO}_{2}(46 \%)$, followed by $\mathrm{PM}_{2.5}(40 \%), \mathrm{PM}_{10}(37 \%)$, and $\mathrm{CO}(19 \%) . \mathrm{SO}_{2}$ and $\mathrm{O}_{3}$ contrarily recorded an overall increase of $40 \%$ and $41 \%$. These results wherein vehicular pollutants recorded the maximum drop indicate that reduced vehicular traffic primarily influenced air quality improvement during the lockdown.
\end{abstract}

Keywords Air quality $\cdot$ COVID-19 $\cdot$ Metro cities $\cdot$ Traffic peaks hours

\section{Introduction}

In late December 2019, an outbreak of a highly contagious disease caused by the novel coronavirus, SARS-CoV-2, emerged in Wuhan City, China, reported as a cluster of pneumonia cases in earlier stages. The disease was identified as coronavirus disease (COVID-19) by the Chinese authorities on 7 January 2020. Furthermore, with the outbreak of disease

Responsible Editor: Amjad Kallel

Rajeev Kumar Mishra rajeevkumarmishra@dtu.ac.in

1 Department of Environmental Engineering, Delhi Technological University, Delhi 110042, India

2 Centre of Excellence in Energy and Environment Studies, Deenbandhu Chhotu Ram University of Science and Technology, Murthal (Sonepat), Haryana 131039, India spreading throughout the world, the World Health Organization (WHO) recognised it as a 'pandemic' on 11 March 2020 (Cucinotta and Vanelli 2020). The critical sources of infection are patients infected with the novel coronavirus. Since then, there have been an enormous number of detected cases worldwide; as of 31 May 2020, the world has recorded 5,934,936 cases and 367,166 deaths due to the novel coronavirus disease (World Health Organisation 2020). Without any vaccine in hand, the authorities worldwide resorted to lockdown, a unique and only solution to constraint the exponential increase in cases. The first coronavirus case was reported in India on 30 January 2020, in Kerala (Nair 2020). Soon the virus spread to other Indian states and metros like Delhi and Mumbai. On 22 March 2020, the Indian Prime Minister called for a 'Janata Curfew', a 14-h informal curfew to practice social distancing nationwide. After the 14-h social distancing initiative, India's government decided to impose a nationwide lockdown on 24 March 2020 to contain the rapidly spreading epidemic (Chaurasiya et al. 2020). Under this first 
phase of lockdown, there was a complete clampdown on government offices, commercial and private establishments, industrial establishments, educational institutions, places of worship, and all transport services - air, water, and land, barring essential services such as healthcare, grocery shops, pharmacies, milk booths, banks, ATMs, petrol pumps, and fire and emergency services (Indian Council of Medical Research 2020). To mitigate hardships experienced by the public, the second phase of lockdown was announced with effect from 15 April 2020, under which additional activities were operationalised outside containment zones (Ministry of Home Affairs 2020). Lockdown guidelines and phases were revised periodically to ease outdoor activity restrictions, with the $2^{\text {nd }}, 3^{\text {rd }}$, and $4^{\text {th }}$ phase culminating on 3 May, 17 May, and 31 May, respectively. On 1 June 2020, the Government of India announced Unlock 1.0, in which prevailing restrictions in non-containment areas were lifted, accounting for the economic downturn resulting from a halt on commercial activity (Saha and Chouhan 2020). Lockdown was imposed to reduce the spread of COVID-19 infection, and it has emerged as one of the mitigating measures to reduce the virus's spread and flatten the curve. Furthermore, restrictions on anthropogenic activities in the country have further improved air quality in various cities. Numerous academic studies have found evidence regarding the reduction in the concentration of criteria pollutants, viz. particulate matter $\left(\mathrm{PM}_{10}\right.$ and $\left.\mathrm{PM}_{2.5}\right)$, nitrogen dioxide $\left(\mathrm{NO}_{2}\right)$, carbon monoxide $(\mathrm{CO})$, ozone $\left(\mathrm{O}_{3}\right)$, and sulphur dioxide $\left(\mathrm{SO}_{2}\right)$. Sarfraz et al. (2020) evaluated satellite images disclosing strong evidence in reducing $\mathrm{NO}_{2}$ in Delhi, Mumbai, and parts of Gujarat. Throughout March, a declining trend was observed in concentration levels of PM and tropospheric $\mathrm{NO}_{2}$ in Delhi, Mumbai, Hyderabad, Kolkata, and Chennai (Singh and Chauhan 2020). Another study analysed reduction in $\mathrm{PM}_{2.5}$ levels along with spatial distribution of aerosol optical depth (AOD) using satellite imagery; a significant reduction in $\mathrm{PM}_{2.5}$ levels was found due to lockdown in cities with larger traffic volumes in five Indian cities of about 54\% (Kumar et al. 2020). Likewise Mahato et al. (2020) studied seven pollutant parameters $\left(\mathrm{PM}_{10}, \mathrm{PM}_{2.5}, \mathrm{SO}_{2}, \mathrm{NO}_{2}, \mathrm{CO}\right.$, $\mathrm{O}_{3}$, and $\mathrm{NH}_{3}$ ) for 34 stations in Delhi; the results of this study concluded that $\mathrm{PM}_{10}$ and $\mathrm{PM}_{2.5}$ witnessed maximum reduction followed by $\mathrm{NO}_{2}, \mathrm{CO}$, and $\mathrm{NH}_{3}$; along with that, a slight increase in $\mathrm{O}_{3}$ concentration was found due to decrease in $\mathrm{NO}_{2}$ and particulate matter concentrations. Agarwal et al. (2020) conducted a comparative study on air quality in India and China's cities during the lockdown. The study found a gradual decline of $\mathrm{PM}_{2.5}$ levels; on the other hand, a sharp decline in concentrations on $\mathrm{NO}_{2}$ was found during the first lockdown. Sharma et al. (2020) also studied the six criteria pollutants in 22 different regions, and the studies concluded a significant reduction in AQI compared to previous years. Additionally, a significant correlation in northern and eastern regions was also observed in 2020 due to significant regional transport than in previous years. Similarly, some studies have focussed on air quality change due to lockdown in specific Indian states, like Sharma et al. (2020), focussed on criteria pollutants in Rajasthan.

With several studies conducted throughout India on the effects of lockdown on air quality, most studies have focussed upon the 24-h average pollutant concentration. The present research focuses upon 1-h ambient air pollutant concentration of six criteria pollutants in five centres while studying the role and effect of transport in pollutant concentration in peak and off-peak (non-peak) hours. Peak and off-peak hours are representative periods of high and moderate road traffic, respectively. They are characterised by high traffic volume, and peak hours record the most significant pollutant concentrations during the day. Furthermore, to investigate the role of other parameters like a halt in construction and meteorology, correlations have also been studied between drop-in pollutant concentrations and relevant parameters.

\section{Methodology}

\section{Study locations}

In the present study of air quality comparison before and after the imposition of lockdown, India's most commercialityactive hubs, including major metropolitan cities of Bangalore, Chennai, Delhi, Kolkata, and Mumbai, have been selected (Table S1, Fig. 1). The reason behind choosing these

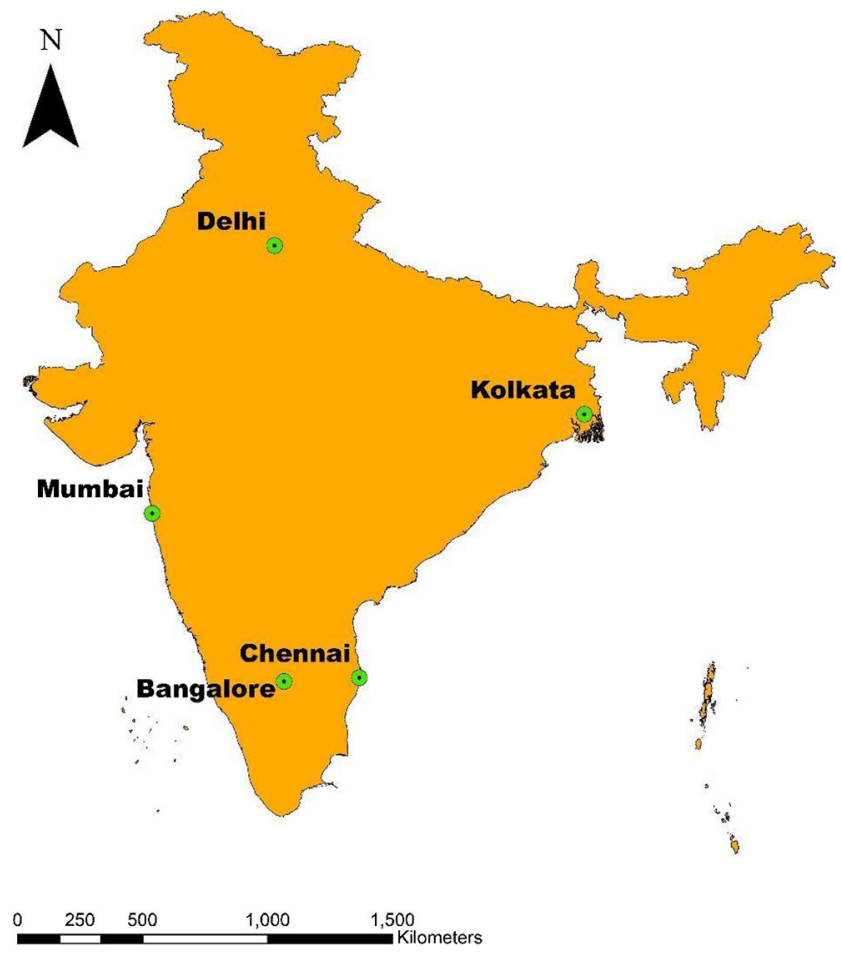

Fig. 1 Study locations and metropolitan cities of India 
cities is the high degree of economic, industrial, commercial, and tourism activities associated with them, cessation in which the lockdown will cause a statistically significant drop in aerosol emissions. Despite their similarities as the country's economic engine, these metro cities vary considerably in their topographical and meteorological characteristics. The lockdown period, i.e. 24 March to 31 May, represents the summer season in all the study locations, but different geographical locations present vacillating conditions for the transportation of pollutants. Detailed information on the meteorological conditions and individual features of the 5 Indian cities has been shown in Tables S2 and S3.

\section{Data collection}

Hourly data for the criteria pollutants, viz. $\mathrm{PM}_{2.5}, \mathrm{PM}_{10}, \mathrm{NO}_{2}$, $\mathrm{SO}_{2}, \mathrm{O}_{3}$, and $\mathrm{CO}$, have been acquired from Continuous Ambient Air Quality Monitoring Stations (CAAQMS) (CPCB 2010), which is managed by Central Pollution Control Board (CPCB), Delhi. This data has been collected for the period of 1 February to 31 May for 2019 and 2020. Apart from pollutants, meteorological data, viz. wind speed, wind direction, solar radiation, and rainfall, have also been collected from CAAQMS.

\section{Data analysis}

Hourly data from all the monitoring stations in a city have been averaged to obtain mean hourly pollutant concentrations. The hourly data collected has been grouped into three averaged types: first into 24-h average, then into evening peak hours average, morning peak hours average, and off-peak hours average. The time slot for evening peaks and morning peaks are 08:00 to 10:00 $\mathrm{h}$ and for morning peak and evening peak from 18:00 h to 21:00 h. The lockdown period $25 \mathrm{March}$ to 31 May 2020 has been divided into 4 phases as per government guidelines: phase 1, 25 March to 14 April; phase 2, 15 April to 3 May; phase 3, 4 May to 17 May; and phase 4, 18 May to 31 May. The data analysis also involved finding the drop percentages trend between the different phases of lockdown with respect to (wrt.) the pre-lockdown period and the base year 2019.

The drop percentages were calculated using the following equations:

\section{Percentage drop wrt.before lockdown}

$$
=\left[\left(C_{B L}-C_{L D}\right) / C_{B L}\right] \times 100
$$

Percentage drop wrt.2019

$$
=\left[\left(C_{2019}--C_{2020}\right) / C_{2019}\right] \times 100
$$

where $C_{\mathrm{BL}}$ is the pollutant concentration before the lockdown, $C_{\mathrm{LD}}$ is the pollutant concentration during the lockdown, $C_{2019}$ is the pollutant concentration during 2019 (exact dates as 2020), and $C_{2020}$ is the pollutant concentration during 2020 (lockdown dates).

\section{Result and discussion}

Hourly pollutant concentrations have been plotted from 1 February to 31 May for 2019 and 2020 (Figures S1-S5 of supplementary material). A trend discernible in most cities, the pollutant concentration in 2019 has reduced steadily as months proceed due to increased mixing height rendered by rising temperatures with the onset of summer (Mor et al. 2021). Contrastingly in 2020, a sharp, more conspicuous drop is visible as the line chart enters the lockdown period (Figure S1-S5). A trend of gradually increasing concentrations can also be observed as the lockdown phases progressed, except in Kolkata, which received heavy rainfall during the lockdown, leading to a further decrease in pollutant concentration..

\section{Particulate matter}

\section{$\mathrm{PM}_{10}$}

Average hourly $\mathrm{PM}_{10}$ concentrations in Delhi decreased by $41 \%$, $22 \%, 15 \%$, and $-10 \%$ in phases $1,2,3$, and 4 , respectively, with respect to before lockdown $\mathrm{PM}_{10}$ concentrations (Table 1). It indicates that the maximum decrease in pollutant concentrations was observed during phase 1 when anthropogenic activities stopped immediately due to the sudden imposition of a lockdown. However, as new phases were introduced with vantage on restrictions for anthropogenic activities, the pollutant concentrations started increasing gradually until the 4 th phase. A similar trend was noted in Bangalore, wherein $\mathrm{PM}_{10}$ concentrations decreased by $46 \%, 44 \%, 31 \%$, and $39 \%$, respectively (Table 1 ).

The maximum decrease in average 24-h concentration across all phases was observed in Kolkata, followed by Bangalore, Delhi, and Mumbai. In Mumbai, $\mathrm{PM}_{10}$ concentrations during lockdown were consistently more significant than

Table 1 Percentage decrease in $\mathrm{PM}_{10}$ concentrations with respect to before lockdown

\begin{tabular}{lllll}
\hline Phase & Bangalore & Delhi & Kolkata & Mumbai \\
\hline 1 & 46 & 41 & 38 & -36 \\
2 & 44 & 22 & 68 & -56 \\
3 & 31 & 15 & 62 & -49 \\
4 & 39 & -10 & 63 & -58 \\
Average drop & 40 & 17 & 58 & -50 \\
\hline
\end{tabular}

\# Due to unavailability of $\mathrm{PM}_{10}$ data of Chennai for the study period, the present study doesn't include any discussion for the same 
before lockdown concentrations by $36 \%, 56 \%, 49 \%$, and $58 \%$ in the 4 phases, respectively (Table 1). The average decrease in hourly $\mathrm{PM}_{10}$ concentrations in all phases has also been presented for all the cities in Table 1.

As seen in Fig. S1-S5, it can be deduced that the majority of $2019 \mathrm{PM}_{10}$ peak hour concentrations lie above the 24-h National Ambient Air Quality Standards (NAAQS) limits contrary to 2020 peak hour concentrations. It can also be seen that $2020 \mathrm{PM}_{10}$ concentrations are above the NAAQS limits majorly before lockdown; as the lockdown begins, the drop is evident. While $\mathrm{PM}_{10}$ (2020) in Delhi has frequently crossed the standard, it remains considerably lower than in 2019 (Fig. 2). Moreover, Delhi's higher $\mathrm{PM}_{10}$ concentrations can be witnessed during the later phases when restrictions were lower. Phase 3 allowed offices and workplaces to function at $33 \%$ capacity while also allowing vehicles with two passengers and 2-wheelers with a single rider. Phase 4 further lifted restrictions on public transport, vehicle passenger limits, and workplace limits. Apart from Mumbai, the difference between 2019 and 2020 is more significant during the initial phases. Still, the difference becomes smaller as the final phases are approached, i.e., restrictions on outdoor activities are eased in pollution with commercial activity.

During both peak and off-peak durations, the maximum decrease, averaged across all phases in $\mathrm{PM}_{10}$ concentrations, was observed in Kolkata $(52 \%, 55 \%)$, followed by Delhi $(46 \%$, $46 \%$ ), Bangalore (44\%, 41\%), and Mumbai (Fig. 2). Although, in phase 1, Kolkata witnessed a 20-30\% decrease in $\mathrm{PM}_{10}$ concentrations, intermittent heavy rainfall days between 20 April and 6 May (phase 2) further abated $\mathrm{PM}_{10}$ concentrations, leading to $60-70 \%$ year on year (y-o-y) reduction. On comparing the $y-0-y$ reduction in $\mathrm{PM}_{10}$ across all phases, it can be noted from Fig. 2 that coastal cities, i.e. Mumbai and Kolkata, showed a more significant reduction in off-peak durations than peak durations, whereas in inland cities, i.e. Delhi and Bangalore, peak-hour $\mathrm{PM}_{10}$ values showed a more significant y-o-y decrease compared to off-peak hours. Moreover, the y-o-y percentage decrease in 24-h $\mathrm{PM}_{10}$ concentrations indicates that the farther away from the sea the city was, the more significant was the decrease in PM concentrations. However, it must be noted that the neutralising effect of the ocean can only be tangible up to a certain distance, after which the oceans exert little-to-no influence on pollution dispersion.

The more pronounced decline during peak hours in Bangalore and Delhi can also be explained by the fact that these two cities have maximum registered vehicles in India. Due to a more extensive fleet of vehicles rendered stationary due to the lockdown, the peak hours have witnessed a more significant decline in $\mathrm{PM}_{10}$ levels, as seen in Fig. 2. Since accurate data on traffic reduction due to the lockdown was not available, to compare the drop in $\mathrm{PM}_{10}$ levels during peak hours with traffic, a regression analysis was plotted between percentage decrease in $\mathrm{PM}_{10}$ evening and morning peak hour concentration with vehicle count of the cities. The $R^{2}$ value of 0.7447 and 0.6329 was obtained, respectively, relating decline during peak hours to the number of vehicles in the city (Fig. 3). The correlation between percentage decrease in average 24-h $\mathrm{PM}_{10}$ concentration during phase 1 with vehicle count displays an overwhelming $R^{2}$ value of 0.9711 (Fig. 3), therefore emphasising that reduced traffic on roads due to the lockdown was a significant cause of the decline in $\mathrm{PM}_{10}$ levels.

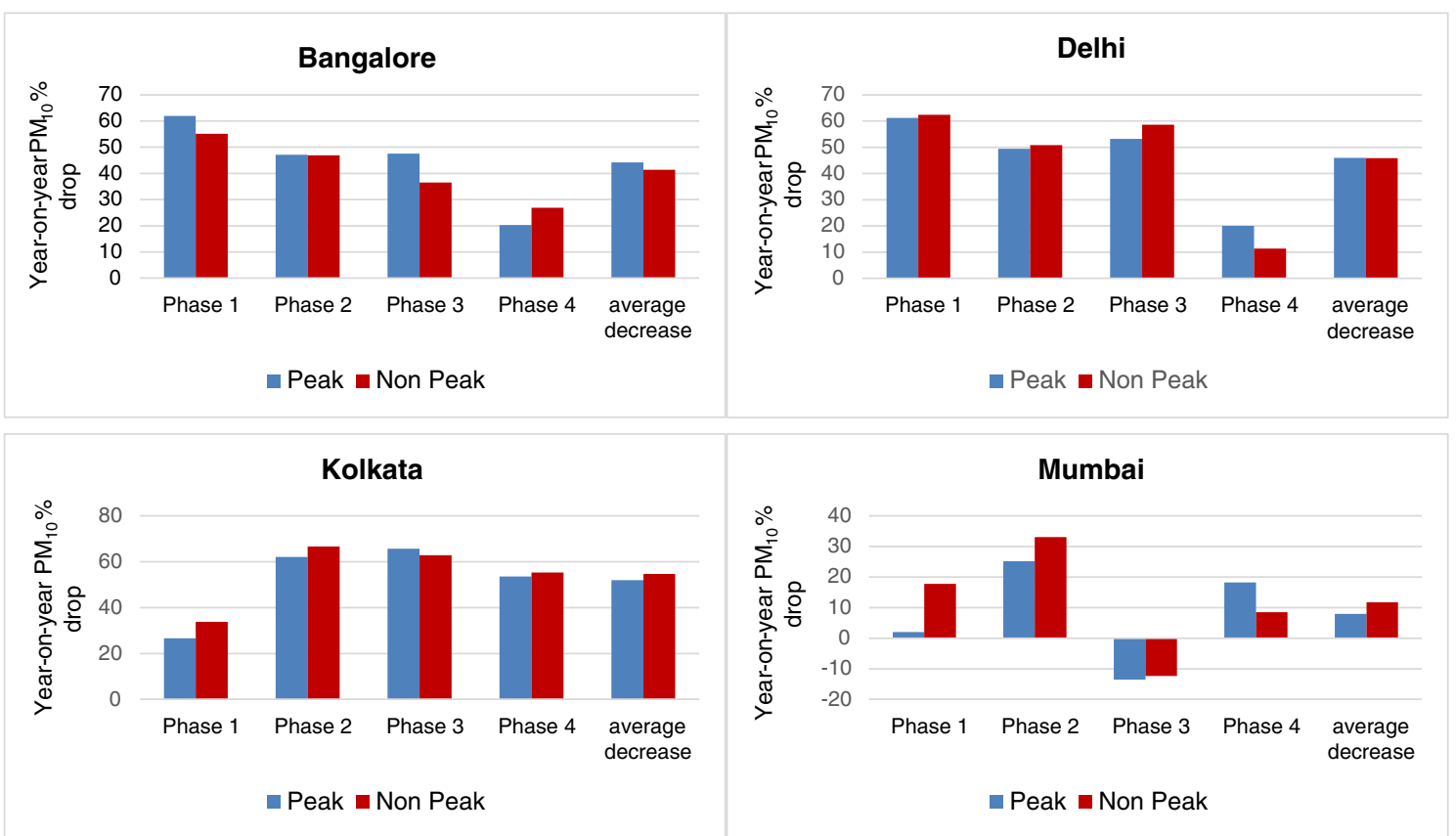

Fig. 2 Phase-wise year-on-year percentage drop in $\mathrm{PM}_{10}$ - peak vs off-peak hours 

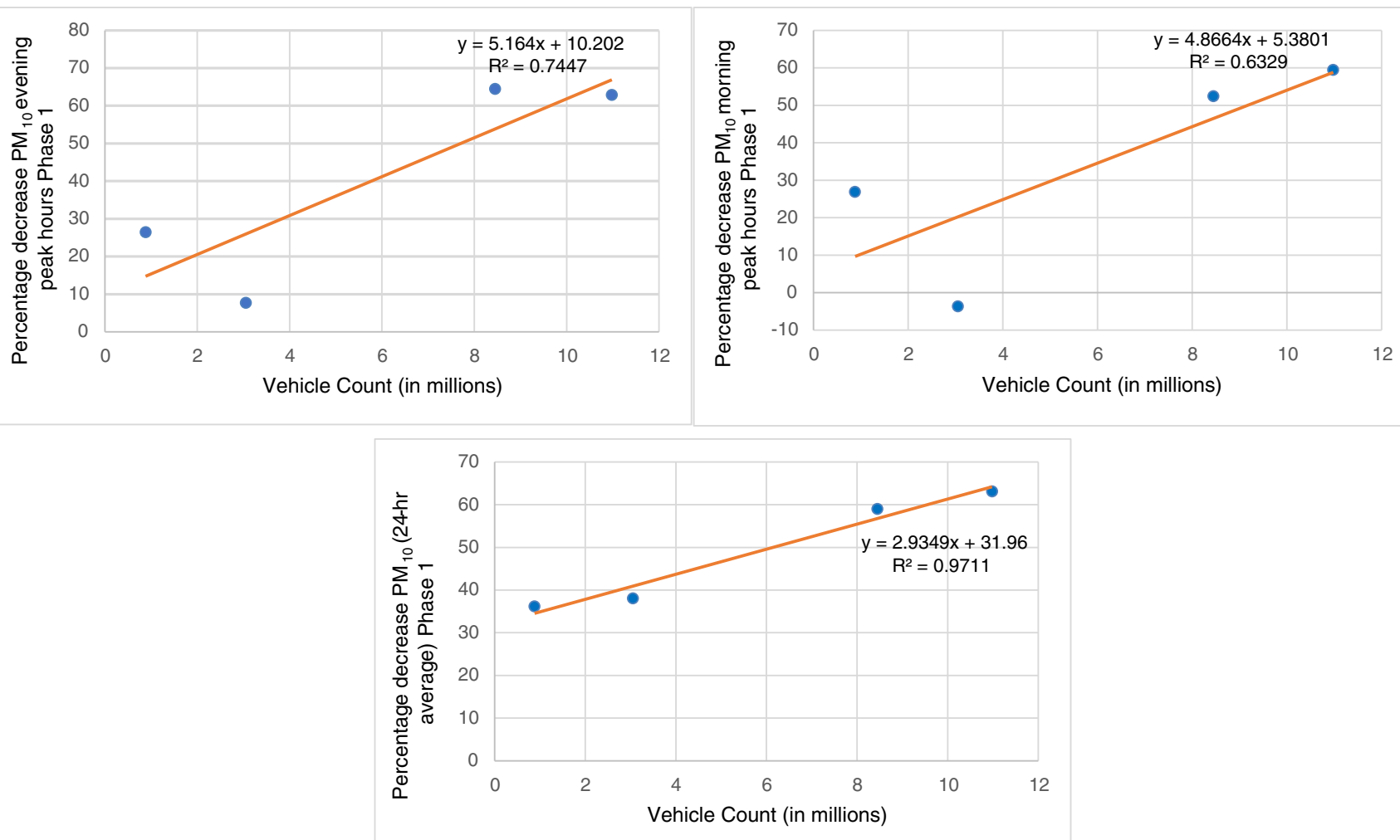

Fig. 3 Vehicle count correlation with year-on-year $\mathrm{PM}_{10}$ percentage drop-evening peak, morning peak, and 24-h average (clockwise from top-left)

Thermal power plants (TPPs) are also significant contributors to particulate pollution; however, even during the lockdown, the TPPs were functioning at an equal capacity, therefore not contributing to the decrease in particulate pollution. Apart from power plants and traffic, there are two critical $\mathrm{PM}_{10}$ emitters. Road dust and construction are the top two contributors to $\mathrm{PM}_{10}$ in Delhi at $24 \mathrm{kt} / \mathrm{year}$ and $14.2 \mathrm{kt} / \mathrm{year}$, respectively (Sharma and Saraf 2018). In Delhi and the other four selected cities, construction and road dust are significant inter-linked contributors to $\mathrm{PM}_{10}$ (CPCB 2010; Guttikunda et al. 2019; NEERI 2010). On regression analysis of the contribution of road dust and construction to $\mathrm{PM}_{10}$ and year-onyear phase $1 \mathrm{PM}_{10}$ decline for each city, the $R^{2}$ value of 0.8032 was obtained (Fig. 4), signifying an essential role of halt in construction activity in decreasing $\mathrm{PM}_{10}$ concentration.

Another trend observed in inland cities is that y-o-y $\mathrm{PM}_{10}$ concentration levels increase with every successive phase, i.e. as commercial activity increases with the introduction of a new phase, the difference between the $\mathrm{PM}_{10}$ levels of 2019 and 2020 also becomes narrower. Morning peak and off-peak hours during phase 3 in Delhi show an anomaly due to the capital's heavy rainfall during this phase. In week 11, after lockdown imposition (17 to 24 May 2020), $2020 \mathrm{PM}_{10}$ concentrations have regularly crossed the 2019 levels due to heavy rainfall in 2019 during this week. This anomaly can also be attributed to Rajasthan's high surface winds this week, which also contributed to greater $\mathrm{PM}_{10}$ concentration in 2020 .
Barring these days, on almost every other occasion, 2020 $\mathrm{PM}_{10}$ concentrations are lower in Delhi. Mumbai was the only city wherein an increase in $\mathrm{PM}_{10}$ concentrations was observed. During morning peak durations, Mumbai witnessed a decline in $\mathrm{PM}_{10}$ only during the second phase (Kumari and Toshniwal 2020; Mahato et al. 2020). In contrast, increases of $4 \%, 23 \%$, and $4 \%$ were observed during the $1^{\text {st }}, 3^{\text {rd }}$, and $4^{\text {th }}$ phase, respectively. However, in evening peak and off-peak timings, Mumbai witnessed a y-o-y increase in $\mathrm{PM}_{10}$ only during the third phase of lockdown. The abnormal increase witnessed in Mumbai with respect to 2019 is attributable to the increase in average wind speeds from 0.13 to $1.28 \mathrm{~m} / \mathrm{s}$. In

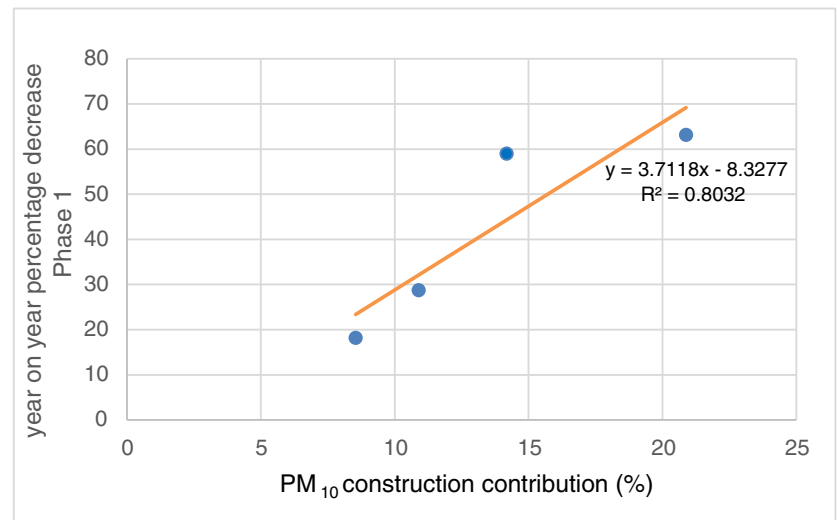

Fig. 4 Year-on-year $\mathrm{PM}_{10}$ percentage drop correlation with construction and road dust contribution to $\mathrm{PM}_{10}$ 
Mumbai being a coastal city, increased wind speed subsequently increases sea-salt concentrations, which are further transported to the air above land (Nair et al. 2005).

\section{$\mathrm{PM}_{2.5}$}

The maximum decrease in $\mathrm{PM}_{2.5}$ with respect to before lockdown averaged across all phases was observed in Kolkata (60\%), followed by Bangalore (44\%), Chennai (42\%), Delhi (23\%), and Mumbai (-46\%) (Table 2). Similar to $\mathrm{PM}_{10}$, Mumbai witnessed an increase in $\mathrm{PM}_{2.5}$ in all the phases. It is hypothesised that the increase in wind speeds wrt. before lockdown is an attributable reason for Mumbai's abnormal PM concentration rise. Figure 5 shows a high positive correlation $\left(R^{2}=0.8706\right)$ between the increase in wind speed and $\mathrm{PM}_{2.5}$ concentrations. Wind speeds directly influence the concentration of particulate matter. It can be seen in Table 2 that while PM has consistently increased wrt. Before Lockdown (BL) in Mumbai, there has been a simultaneous decrease in gaseous pollutants such as $\mathrm{NO}_{2}$ and $\mathrm{CO}$. If the reason behind PM rise was source-related, a similar increase in gaseous pollutants would be expected, which is not the case. Moreover, since the wind direction during the lockdown period was majorly from West to East, i.e. from the sea towards the coast, it can be deduced that sea salt aerosols from the sea may be a contributing factor towards the increased particulate concentration in Mumbai.

For peak and off-peak hours' analysis, a percentage decrease has been calculated concerning 2019 than before lockdown. This is primarily due to the fact that even before lockdown imposition, traffic was lower than usual due to public awareness about the contagious virus. Minimum year-on-year decrease in $\mathrm{PM}_{2.5}$ concentrations has been observed in Mumbai, followed by Delhi in peak and off-peak hours across all phases (Table 3). Like $\mathrm{PM}_{10}$ trends of inland cities, Delhi and Bangalore experienced more significant $\mathrm{PM}_{2.5}$ reductions during peak hours due to a more extensive vehicle fleet. Vehicles being an essential source of $\mathrm{PM}_{2.5}$, on regression analysis of y-o-y percentage decrease in 24-h $\mathrm{PM}_{2.5}$ concentrations with vehicle count in the five cities, an $R^{2}$ value of 0.7163 was obtained (Fig. 6), indicating that the reduction in

Table 2 Percentage decrease in $\mathrm{PM}_{2.5}$ concentrations with respect to before lockdown

\begin{tabular}{llllll}
\hline Phase & Bangalore & Chennai & Delhi & Kolkata & Mumbai \\
\hline 1 & 34 & 26 & 37 & 31 & -24 \\
2 & 42 & 66 & 30 & 71 & -46 \\
3 & 47 & 60 & 15 & 67 & -52 \\
4 & 53 & 18 & 10 & 73 & -62 \\
Average drop & 44 & 42 & 23 & 60 & -46 \\
\hline
\end{tabular}

$\mathrm{PM}_{2.5}$ was more significant in cities with a more extensive vehicle fleet.

Coastal cities being surrounded by the ocean are subject to enormous ventilation potentials, which enhance the pollutant assimilation due to breeze exchange. The ocean's neutralising effect on particulate pollution helps coastal cities maintain their air pollution levels compared to landlocked cities. The absence of pollutant assimilation due to being landlocked prevents the dispersion of air pollutants in cities like Delhi and Bangalore. Therefore, landlocked cities like Delhi have much higher baseline levels of particulate pollution. The high 'before lockdown' levels due to lack of pollutant dispersion in landlocked cities imply that when lockdown is imposed and emissions are drastically minimised, the percentage drop is much more significant than coastal cities with already low baseline particulate pollution (Kumar et al. 2015).

After transport, road dust is the second most significant contributor to $\mathrm{PM}_{2.5}$ concentration levels. However, road dust is directly related to traffic on roads, so lesser traffic can be conferred as the most crucial cause of better air quality. While establishing a correlation, no concrete relation was discerned between $\mathrm{PM}_{2.5}$ and construction activity and industrial activities. This may be because construction activities tend to influence $\mathrm{PM}_{10}$ concentrations more than $\mathrm{PM}_{2.5}$ (Azarmi et al. 2016). In line with anomalous $\mathrm{PM}_{10}$ trends observed in Mumbai, the city observed increasing $\mathrm{PM}_{2.5}$ concentrations on several occasions. During off-peak hours, $\mathrm{PM}_{2.5}$ concentrations in Mumbai increased only during the third phase (Fig. 7). However, in evening and morning peak hours, three phases recorded increasing $\mathrm{PM}_{2.5}$ (Table 3). This trend, however, is specific to Mumbai. In all the other megacities, $\mathrm{PM}_{2.5}$ declined consistently wrt. 2019. Averaging the y-o-y percentage change in all the cities across four phases, it can be observed that the most significant decrease in $\mathrm{PM}_{2.5}$ occurred during off-peak hours (40\%) compared to $32 \%$ and $34 \%$ decline during evening and morning peak hours, respectively. In Bangalore, Chennai, and Delhi, the smallest drop in year-onyear $\mathrm{PM}_{2.5}$ concentrations was observed during the final lockdown phase when there were minimum restrictions on public activity. In Kolkata, lower $\mathrm{PM}_{2.5}$ concentrations in the $4^{\text {th }}$ phase of the lockdown were primarily because of the city's rainfall in May.

\section{Gaseous pollutants}

In addition to the significant PM drop in Indian urban cities, the lockdown also significantly contributed to reducing the concentration of gaseous pollutants.

\section{$\mathrm{NO}_{2}$}

Among all the pollutants, $\mathrm{NO}_{2}$ showed the most significant drop across all the cities. Across all the five selected cities, 
Fig. 5 Correlation between the percentage increase in $\mathrm{PM}_{2.5}$ and percentage increase in WS (Mumbai) w.r.t Before Lockdown

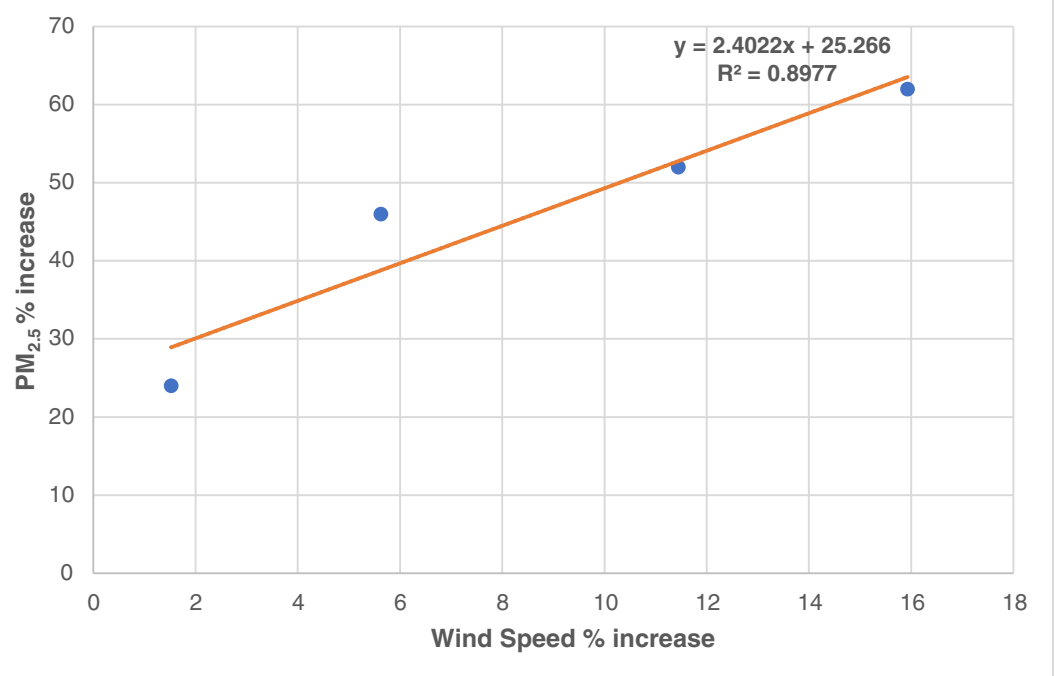

there was an average $51 \%$ drop in concentration levels of $\mathrm{NO}_{2}$ wrt. Before Lockdown (BL) and 46\% drop wrt. 2019. Furthermore, wrt. BL, Mumbai recorded the most significant drop (69\%) in concentration levels of $\mathrm{NO}_{2}$, and in contrast, Chennai recorded the lowest drop (18\%) in concentration levels of $\mathrm{NO}_{2}$. The slight drop recorded in Chennai is primarily due to low $\left(10.50 \mu \mathrm{g} / \mathrm{m}^{3}\right) \mathrm{NO}_{2}$ concentration levels even before lockdown, whereas other cities had much higher $\mathrm{NO}_{2}$ concentration levels than Chennai (Fig. S1-S5). Even wrt. 2019, Chennai recorded the slightest drop in $\mathrm{NO}_{2}(31 \%)$. The significant reduction in concentration levels of $\mathrm{NO}_{2}$ in the selected cities is chiefly attributed to minimal vehicle transportation in the cities; only emergency vehicular

Table 3 Year-on-year percentage decrease in $\mathrm{PM}_{2.5}$ during morning, evening and off-peak hours

\begin{tabular}{llccccc}
\hline Peak & Phase & Bangalore & Chennai & Delhi & Kolkata & Mumbai \\
\hline Morning peak & 1 & 41 & 25 & 45 & 22 & -4 \\
& 2 & 43 & 57 & 36 & 60 & 9 \\
& 3 & 42 & 62 & 43 & 76 & -11 \\
& 4 & 38 & 17 & 23 & 63 & -7 \\
Evening peak & 1 & 60 & 45 & 46 & 16 & -35 \\
& 2 & 57 & 58 & 24 & 63 & -1 \\
& 3 & 59 & 69 & 26 & 63 & -56 \\
Off-peak & 4 & 42 & 29 & 4 & 64 & 2 \\
& 1 & 45 & 41 & 47 & 25 & 18 \\
& 2 & 43 & 62 & 34 & 61 & 33 \\
& 3 & 43 & 79 & 44 & 65 & -12 \\
Peak average & 1 & 50 & 35 & 46 & 19 & -19 \\
& 4 & 43 & 40 & 14 & 63 & 9 \\
& 2 & 50 & 58 & 30 & 61 & 4 \\
& 3 & 50 & 66 & 35 & 70 & -34 \\
& 4 & 40 & 46 & 13 & 64 & -1 \\
\hline
\end{tabular}

transportation was allowed in the first phase of the lockdown (Singh and Chauhan 2020). This supports the research that vehicular traffic is a significant contributor to $\mathrm{NO}_{2}$ concentration levels, especially in megacities. Also, Fig. S1-S5 shows that with ease in lockdown, the concentration levels in $\mathrm{NO}_{2}$ rose in all the cities except Kolkata. The abnormal conditions in concentration levels of $\mathrm{NO}_{2}$ in Kolkata are due to an increase in ambient temperature and wind speed of $7 \%$ and $18 \%$, respectively, from phase 1 to phase 4 . An increase in temperature reduces the atmosphere's stability and increases the mixing height, thereby increasing the vertical mixing of pollutants (Mor et al. 2021). In contrast, Kolkata recorded an average increase of $30 \%$ in concentration levels of $\mathrm{NO}_{2}$ from phase 1 to phase 4 . Across all the study locations, the lowest decrease wrt. 2019 was observed in the final phase of lockdown when restrictions on the general public were least. Among the peak and off-peak hours, the five selected cities recorded the largest drop in $\mathrm{NO}_{2}$ concentration levels in evening peak hours (57\%), followed by morning peak (51\%) and off-peak hours (46\%). From Fig.8, it can be observed that $\mathrm{NO}_{2}$ showed a sharper decrease in peak hours over off-peak hours throughout the study locations. This more significant

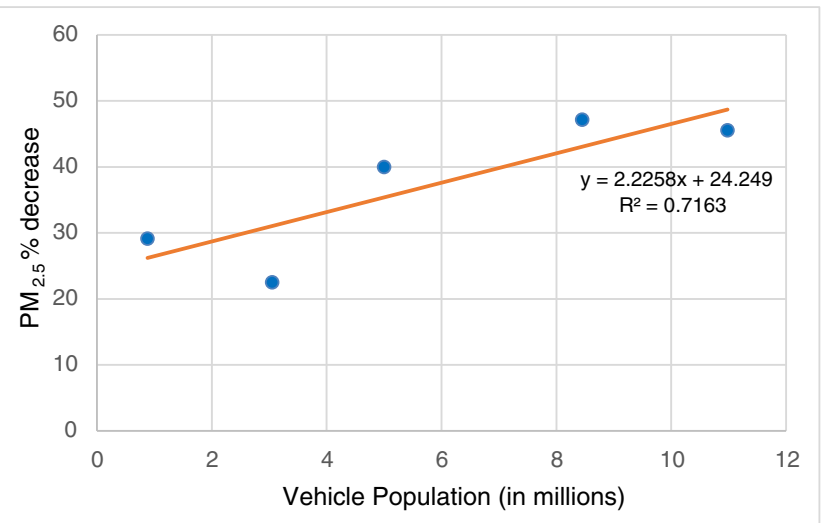

Fig. $6 \mathrm{PM}_{2.5}$ percentage drop correlation with vehicle population 

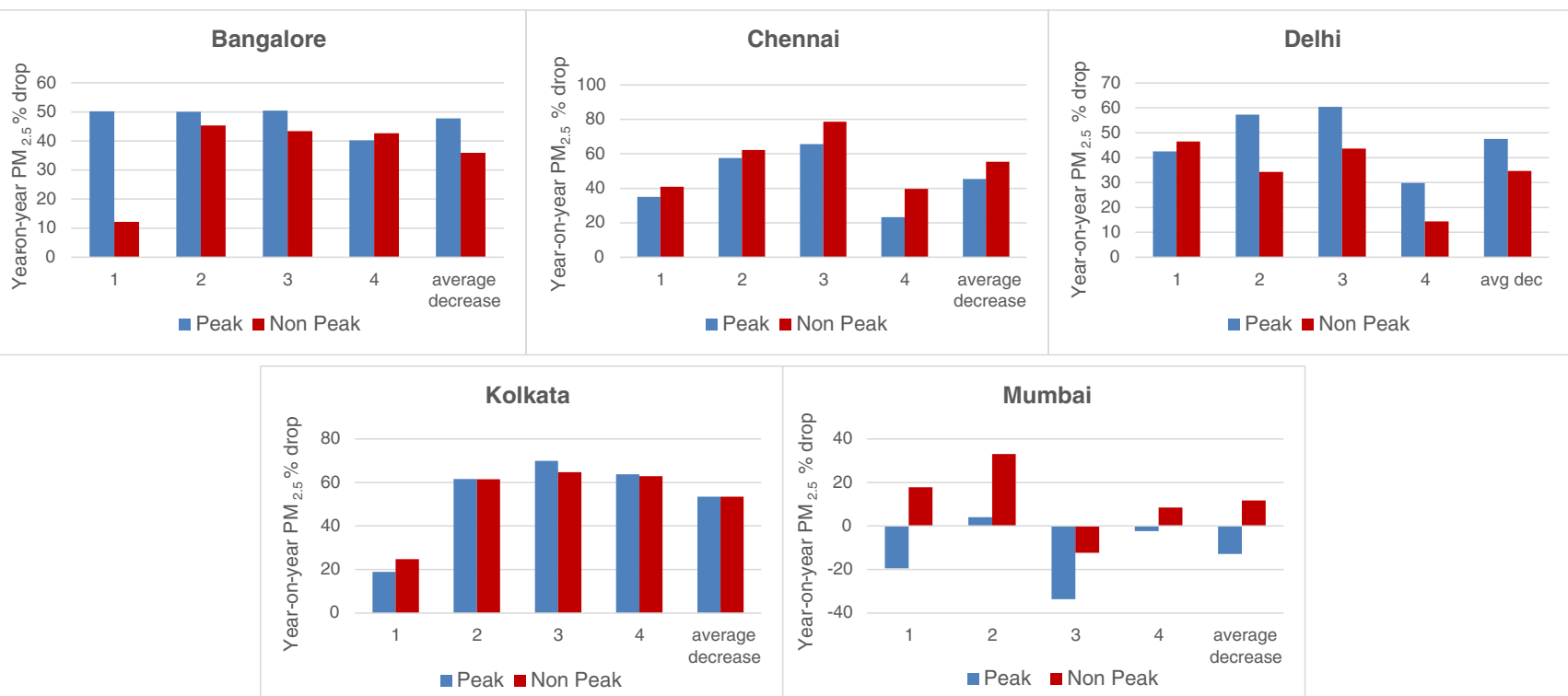

Fig. 7 Phase-wise year-on-year percentage drop in $\mathrm{PM}_{2.5}$ - peak vs off-peak hours

decrease during peak durations suggests the role of traffic in $\mathrm{NO}_{2}$ reduction.

\section{$\mathrm{O}_{3}$}

Interestingly, apart from all the gaseous pollutants, which observed a drop in their respective concentration levels, $\mathrm{O}_{3}$ concentration levels increased by $12 \%$ in Chennai, Delhi, and Kolkata; Bangalore and Mumbai recorded a slight decrease $(7 \%)$ in $\mathrm{O}_{3}$ concentration levels (Fig. S1$\mathrm{S} 5)$. This phenomenon is closely related to the concentration levels of $\mathrm{NO}_{2}$. $\mathrm{NO}_{\mathrm{x}}$ helps in the conversion/ breakdown of $\mathrm{O}_{3}$ into $\mathrm{O}_{2}$. For a long time, it has been debated whether the Indian urban cities are $\mathrm{VOC}$ or $\mathrm{NO}_{\mathrm{x}}$ limited. The trend of $\mathrm{O}_{3}$, as depicted in Fig. S1-S5, shows how the $\mathrm{O}_{3}$ levels increase in most of the cities and, at the same time, decrease in $\mathrm{NO}_{2}$ concentration levels. Through these trends and previously conducted studies by Chen et al. (2021), it is precedent that the $\mathrm{O}_{3}$ production in Indian urban cities is VOC-limited. These results indicate that there is a need to control VOC production alongside $\mathrm{PM}$ and $\mathrm{NO}_{2}$. If VOC production is not limited, the $\mathrm{O}_{3}$ concentration levels could reach alarming levels, crossing the NAAQS for $\mathrm{O}_{3}\left(100 \mu \mathrm{g} / \mathrm{m}^{3}\right)$. It can be seen from Fig. 9 that $\mathrm{O}_{3}$ concentration had increased consistently during peak hours across all the cities. However, during off-peak
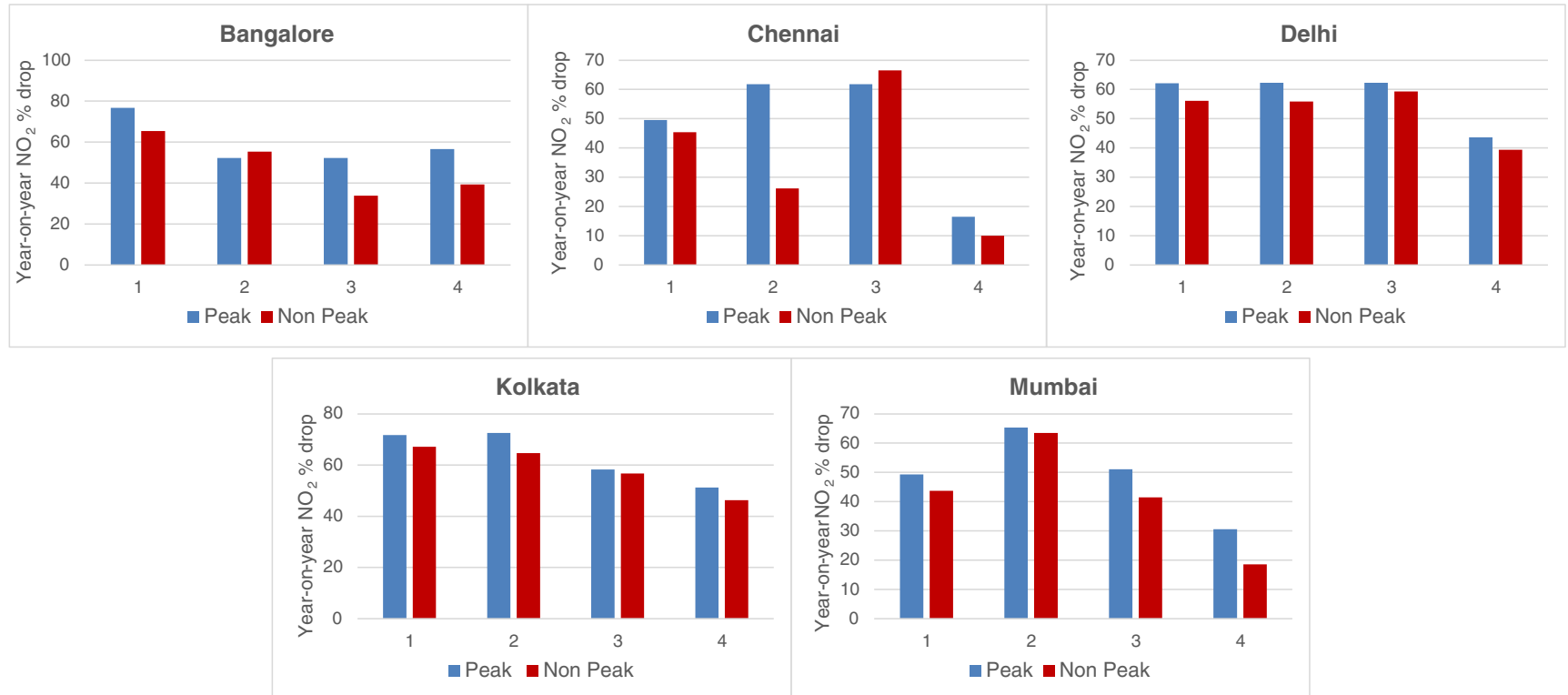

Fig. 8 Phase-wise year-on-year percentage decrease in $\mathrm{NO}_{2}$ - peak vs non-peak hours 

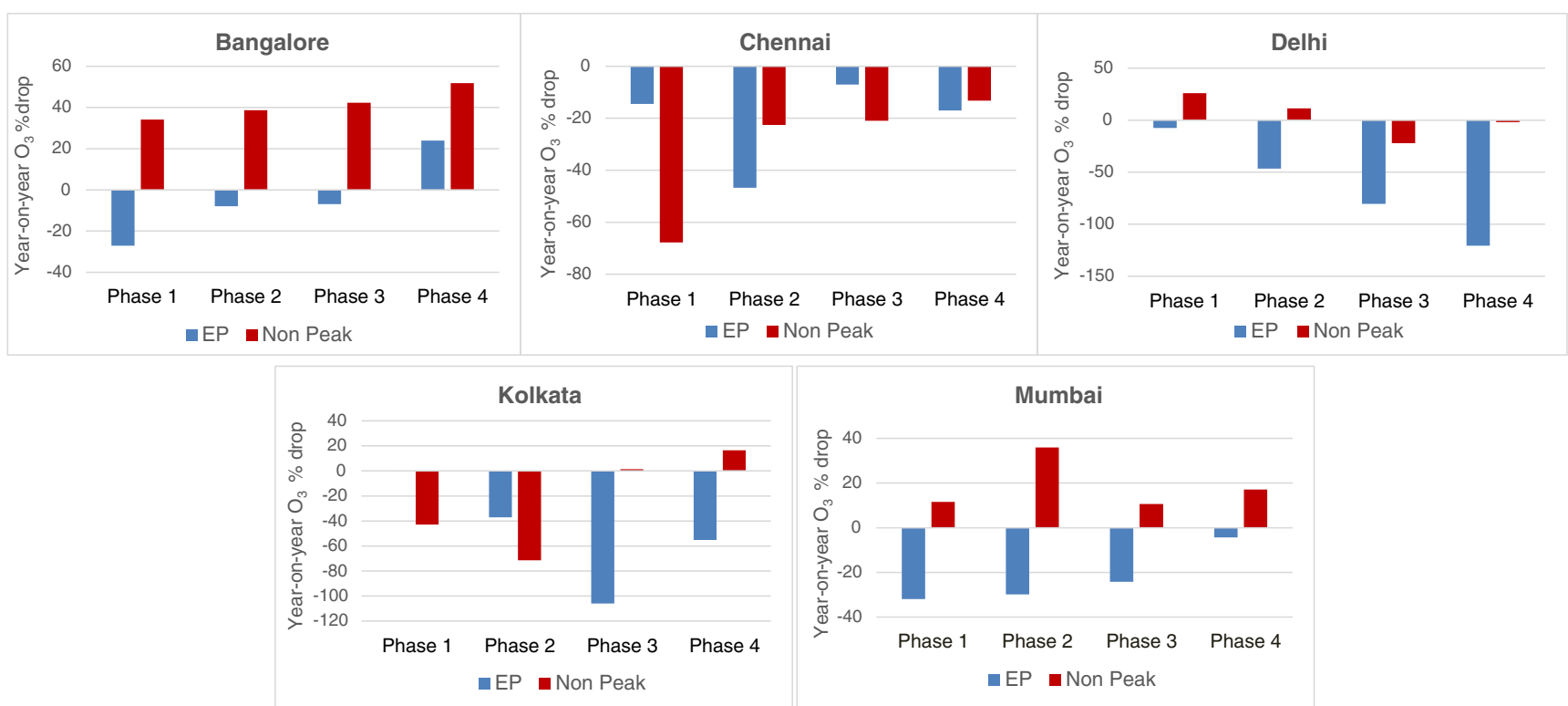

Fig. 9 Phase-wise year-on-year percentage decrease in $\mathrm{O}_{3}$ - evening peak vs non-peak hours

hours, $\mathrm{O}_{3}$ has somewhat decreased in Delhi and Mumbai. It further adds to the hypothesis that ozone concentrations are inversely related to $\mathrm{NO}_{2}$ concentrations. $\mathrm{NO}_{2}$ shows a more significant decrease during peak hour durations, while ozone concentration increases during peak hours.

Another reason for $\mathrm{O}_{3}$ increases across all cities is attributed to a smaller decrease in CO. Data showed that ozone concentrations increased whenever the percentage decrease in $\mathrm{CO}$ was lower than $20 \%$. Since $\mathrm{CO}$ is involved in $\mathrm{O}_{3}$ formation, the more significant the reduction in $\mathrm{CO}$, the greater decrease should be in $\mathrm{O}_{3}$ (NRC 1999). The correlation between the percentage decrease in $\mathrm{CO}$ and $\mathrm{O}_{3}$ in all cities and all phases indicates a positive correlation $\left(R^{2}=0.5638\right)$, which suggests the possibility that the ozone increase can be attributable to slowly declining CO (Fig. 10).

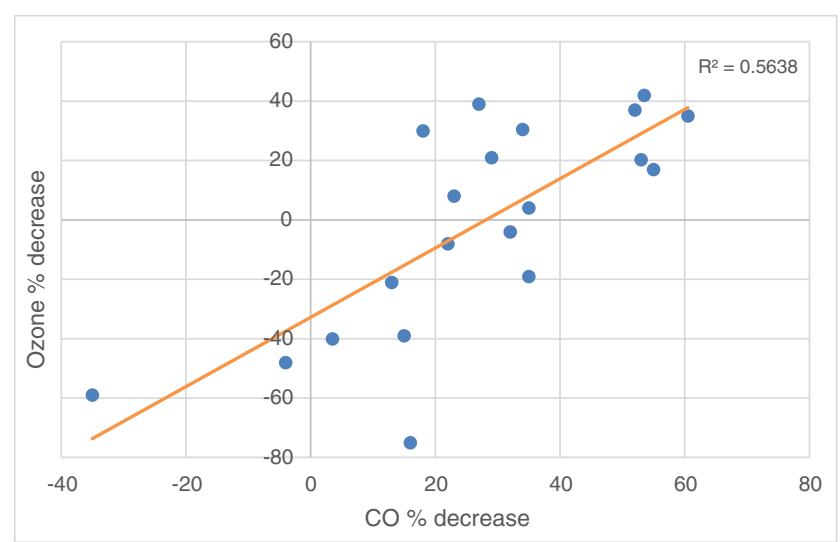

Fig. 10 Percentage decrease in ozone correlation with percentage decrease in $\mathrm{CO}$

\section{CO}

In the concentration levels of $\mathrm{CO}$ across all the five selected cities, there was an average $29 \%$ drop between before lockdown and phase 1 . The year-on-year average decrease for all the cities except Mumbai due to lack of available data was $23 \%$. The lowest year-on-year decrease was observed in Kolkata (16\%), while the highest drop was observed in Delhi (46\%) (Fig. S1-S5). Across phase 1 and phase 4, the cities of Delhi and Chennai observed an increase in CO concentration levels by $50 \%$ and $75 \%$, respectively, resulting from the reduction in restrictions across phases. However, Mumbai and Kolkata saw a further decrease in CO concentrations by $39 \%$ and $29 \%$, respectively. At the same time, Bangalore has a minor reduction of only $4 \%$ (Fig. S1-S5).

From Fig. 11, in Bangalore and Kolkata, CO has consistently increased with respect to 2019 during off-peak hours. This increase can be attributed to the fact that in 2019, Bangalore and Kolkata already had the lowest CO concentrations, $0.76 \mathrm{mg} / \mathrm{m}^{3}$ and $0.52 \mathrm{mg} / \mathrm{m}^{3}$, respectively, compared to $1.08 \mathrm{mg} / \mathrm{m}^{3}, 1.67 \mathrm{mg} / \mathrm{m}^{3}$, and $0.82 \mathrm{mg} / \mathrm{m}^{3}$ for Delhi, Mumbai, and Chennai, respectively. However, unlike off-peak durations, peak hours presented a consistent decline in CO concentrations compared to 2019, which can be owed majorly to reducing traffic volume due to the lockdown since vehicles are the single largest source of CO in Delhi.

\section{$\mathrm{SO}_{2}$}

The $\mathrm{SO}_{2}$ concentration in the selected five cities observed an average decline of $23 \%$ in phase 1 with respect to Before 

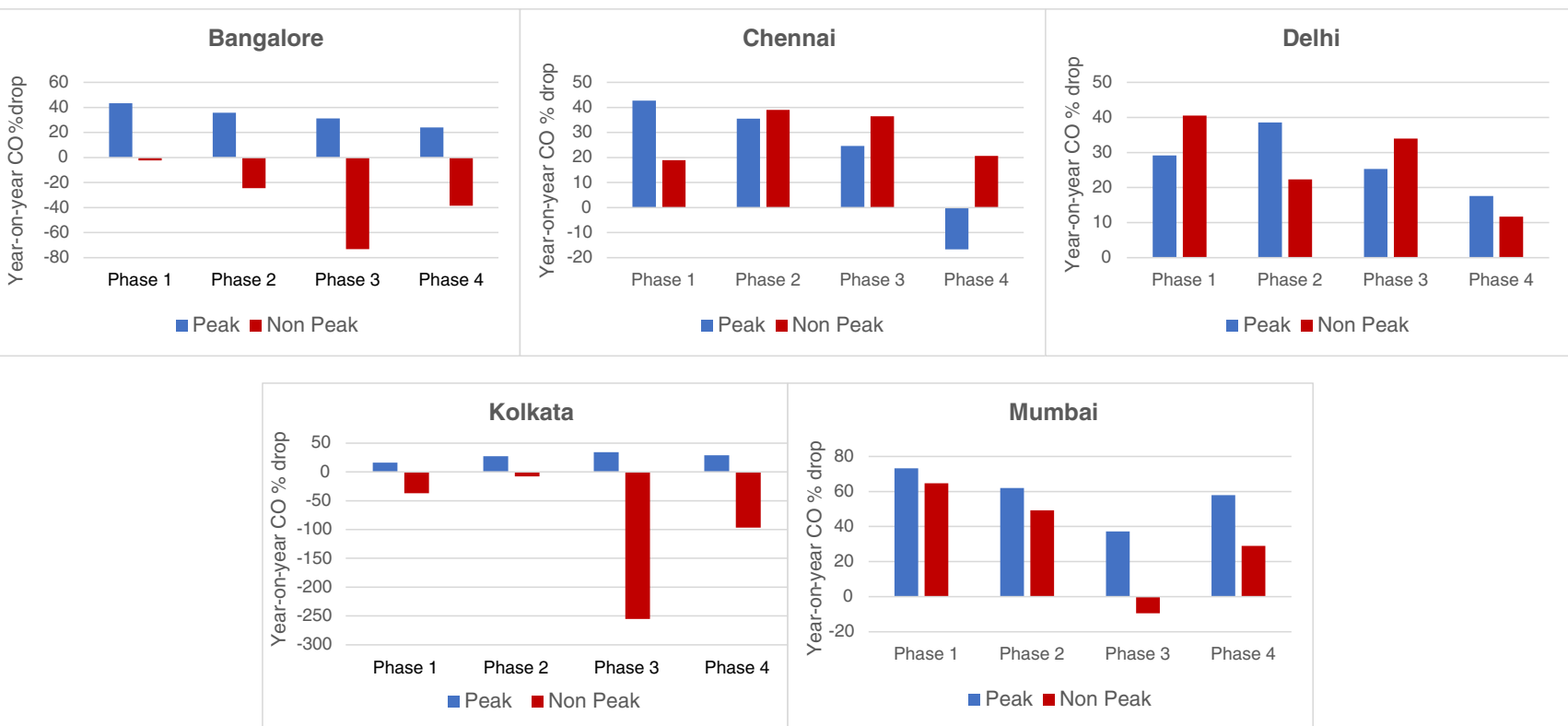

Fig. 11 Phase-wise year-on-year percentage decrease in $\mathrm{CO}$ - peak vs non-peak hours

Lockdown (BL) in 2020. The slightest drop was recorded in Delhi (7\%) (Fig. S1). Delhi's low decline can be attributed to the early launch of BS-VI fuel in India's National Capital Territory. India shifted from BS-IV fuel to directly BS-VI fuel, which implies five times decrease in the fuel's sulphur content. Earlier, the fuel used to have $50 \mathrm{ppm}$ sulphur, whereas the new BS-VI fuel contains just 10 ppm sulphur. In Delhi, the BS-VI fuel was launched in April 2019; however, it was launched in April 2020 in the rest of the nation (BCMT 2020). Every city observed an increase in concentration levels of $\mathrm{SO}_{2}$ as the phases progressed and lockdown restrictions started to ease, except Kolkata.
In contrast, Kolkata recorded a further decrease of $47 \%$ in phase 4 with respect to phase 1 in 2020 (Fig. S3). The further drop in Kolkata is mainly due to meteorological conditions attributed to Kolkata, especially wind speed and atmospheric temperature. Progressive increase in temperature across phases increased mixing height. The wind speeds in Kolkata rose by $57 \%$ from phase 1 to phase 4 in 2020 (Tasić et al. 2013). However, from Fig. 12, it can be seen that in terms of year on year change, in Kolkata and Bangalore, $\mathrm{SO}_{2}$ concentration increased during peak hours. This anomaly is mainly because $\mathrm{SO}_{2}$ concentrations were already low in 2019 in these two cities during these dates.

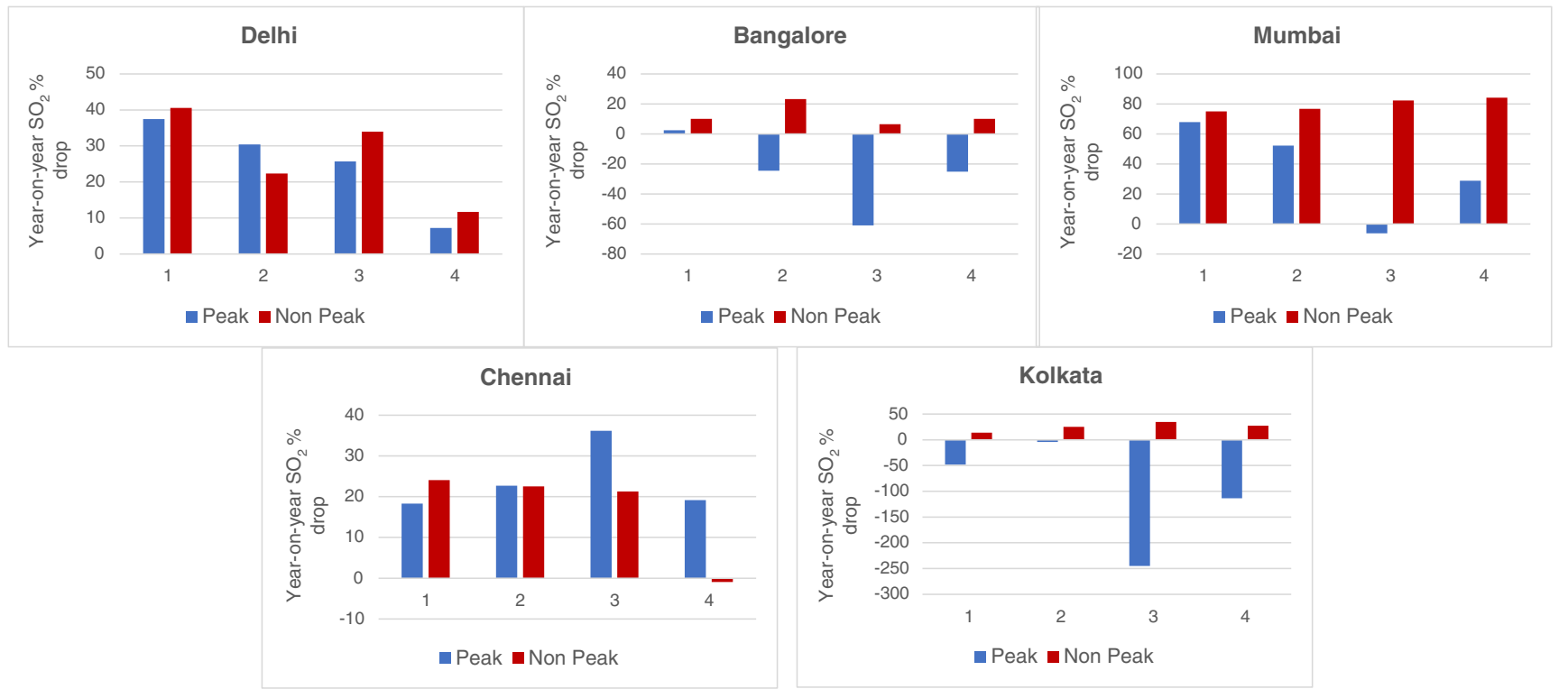

Fig. 12 Phase-wise year-on-year percentage decrease in $\mathrm{SO}_{2}$ - peak vs off-peak hours 


\section{Conclusion}

A comparison of five megacities has been studied to discern the role of reduced traffic, halt in construction, meteorological parameters, and other anthropogenic factors in ameliorating air quality due to the imposition of a lockdown. For peak hours and off-peak hours analyses, a comparison was made with 2019 rather than before lockdown. The holistic analysis of pollutant concentrations of $\mathrm{PM}_{10}, \mathrm{PM}_{2.5}, \mathrm{NO}_{2}, \mathrm{SO}_{2}, \mathrm{CO}$, and $\mathrm{O}_{3}$ resulting from this study lends several conclusive outcomes. $\mathrm{PM}_{10}$ and $\mathrm{PM}_{2.5}$ recorded a maximum overall drop in Kolkata $(58 \%, 60 \%)$ and an overall increase in Mumbai $(50 \%, 46 \%)$ mainly due to a consistent rise in wind speed in the respective cities. High positive correlations of 24-h average drop percentages have been recorded with vehicle populations for $\mathrm{PM}_{10}\left(R^{2}=0.97\right)$ and $\mathrm{PM}_{2.5}\left(R^{2}=0.72\right)$, relating drop in particulate pollution to reduced road traffic. $\mathrm{PM}_{10}$ drop percentages also showed a significant correlation $\left(R^{2}=0.80\right)$ with dust contribution to total particulate emissions. Among gaseous pollutants, maximum drop averaged across wrt. Before Lockdown (BL) in all studies, locations were recorded in $\mathrm{NO}_{2}(51 \%)$, followed by $\mathrm{CO}$ $(29 \%)$ and $\mathrm{SO}_{2}(23 \%)$, while ozone recorded an overall increase (4\%). Among all pollutants, wrt. 2019, the maximum drop was observed in $\mathrm{NO}_{2}(46 \%)$, followed by $\mathrm{PM}_{2.5}(40 \%), \mathrm{PM}_{10}(37 \%)$, and $\mathrm{CO}(19 \%)$, suggesting that vehicle-dominated pollutants declined by the greatest during the lockdown. The more significant decrease in $\mathrm{NO}_{2}$ and $\mathrm{CO}$ in peak hours over off-peak hours further suggests the role of reduced traffic volume. The lowest drop wrt. before lockdown was observed in the case of $\mathrm{SO}_{2}$ (23\%), primarily due to $\mathrm{SO}_{2}$ not being a primary vehicular pollutant. Instead, $\mathrm{SO}_{2}$ is linked with power plants that were running at equal capacity during the lockdown. The increase in ozone concentrations can be attributed to low $\mathrm{NO}_{2}$ conditions rendered by reduced traffic since $\mathrm{NO}_{2}$ is involved in ozone decomposition, and a lower decrease in $\mathrm{CO}$, which is involved in tropospheric ozone formation. The reduction in ozone concentrations showed a positive correlation with the decline in CO $\left(R^{2}=0.5638\right)$. The present study will help policymakers identify the factors that led to the changes in concentration levels of criteria pollutants and enable them to draft a response plan for high air pollution incidents in metro cities.

Supplementary Information The online version contains supplementary material available at https://doi.org/10.1007/s12517-021-07777-x.

Acknowledgements The authors are very much thankful to Advance Air and Acoustics Research Lab, Delhi Technological University, for providing necessary facilities to conduct this study.
Availability of data and material The data used in the current study have been taken from CPCB and is available in the public domain. Code availability Not applicable

\section{Declarations}

Conflict of interest The authors declare no competing interests.

\section{References}

Agarwal A, Kaushik A, Kumar S, Mishra RK (2020) Comparative study on air quality status in Indian and Chinese cities before and during the COVID-19 lockdown period. Air Qual Atmos Health 13:11671178. https://doi.org/10.1007/s11869-020-00881-z

Azarmi F, Kumar P, Marsh D, Fuller G (2016) Assessment of the longterm impacts of PM10 and PM2.5 particles from construction works on surrounding areas. Environ Sci Process Impacts 18:208-221. https://doi.org/10.1039/c5em00549c

BCMT (2020) BS 6 / BS VI 2 Wheelers in India India Travel Forum, BCMTouring. India Travel Forum, BCMTouring. URL https:// www.bcmtouring.com/forums/threads/bs-6-bs-vi-2-wheelers-inindia.76056/ Accessed 19 Dec 2020

Chaurasiya P, Pandey P, Rajak U, Dhakar K, Verma M, Verma T (2020) Epidemic and challenges of coronavirus disease-2019 (COVID-19): India response. SSRN Electron J. https://doi.org/10.2139/ssrn. 3569665

Chen Y, Beig G, Archer-Nicholls S, Drysdale W, Acton WJF, Lowe D, Nelson B, Lee J, Ran L, Wang Y, Wu Z, Sahu SK, Sokhi RS, Singh V, Gadi R, Nicholas Hewitt C, Nemitz E, Archibald A, McFiggans G, Wild O (2021) Avoiding high ozone pollution in Delhi, India. Faraday Discuss 226:502-514. https://doi.org/10.1039/d0fd00079e

CPCB (2010) Air quality monitoring, emission inventory and source apportionment study for Indian cities. Cent. Pollut. Control Board, India 12

Cucinotta D, Vanelli M (2020) WHO declares COVID-19 a pandemic. Acta Biomed. https://doi.org/10.23750/abm.v91i1.9397

Guttikunda SK, Nishadh KA, Gota S, Singh P, Chanda A, Jawahar P, Asundi J (2019) Air quality, emissions, and source contributions analysis for the Greater Bengaluru region of India. Atmos Pollut Res 10:941-953. https://doi.org/10.1016/j.apr.2019.01.002

Indian Council of Medical Research (2020) Press Release. Indian Counc. Med. Res. Gov. India. URL https://main.icmr.nic.in/press-release. Accessed 9 Dec 2020

Kumar P, Khare M, Harrison RM, Bloss WJ, Lewis AC, Coe H, Morawska L (2015) New directions: air pollution challenges for developing megacities like Delhi. Atmos Environ 122(December): 657-661. https://doi.org/10.1016/j.atmosenv.2015.10.032

Kumar P, Hama S, Omidvarborna H, Sharma A, Sahani J, Abhijith KV, Debele SE, Zavala-Reyes JC, Barwise Y, Tiwari A (2020) Temporary reduction in fine particulate matter due to 'anthropogenic emissions switch-off' during COVID-19 lockdown in Indian cities. Sustain Cities Soc 62:102382. https://doi.org/10.1016/j.scs. 2020.102382

Kumari P, Toshniwal D (2020) Impact of lockdown measures during COVID-19 on air quality- a case study of India. Int J Environ Health Res 00:1-8. https://doi.org/10.1080/09603123.2020. 1778646

Mahato S, Pal S, Ghosh KG (2020) Effect of lockdown amid COVID-19 pandemic on air quality of the megacity Delhi, India. Sci Total Environ 730:139086. https://doi.org/10.1016/j.scitotenv.2020. 139086

Ministry of Home Affairs (2020) Circulars for Covid-19 | Ministry of Home Affairs | GoI. Minist. Home Aff. Gov. India. URL https:// 
www.mha.gov.in/notifications/circulars-covid-19. Accessed 9 Dec 2020

Mor S, Kumar S, Singh T, Dogra S, Pandey V, Ravindra K (2021) Impact of COVID-19 lockdown on air quality in Chandigarh, India: understanding the emission sources during controlled anthropogenic activities. Chemosphere 263:127978. https://doi.org/10.1016/j. chemosphere.2020.127978

Nair S (2020) Covid-19 pandemic in India updates: coronavirus status by city and state. URL https://www.pharmaceutical-technology.com/ news/india-covid-19-coronavirus-updates-status-by-state/. Accessed 8 Dec 2020

Nair PR, Parameswaran K, Abraham A, Jacob S (2005) Winddependence of sea-salt and non-sea-salt aerosols over the oceanic environment. J Atmos Solar Terrestrial Phys 67:884-898. https:// doi.org/10.1016/j.jastp.2005.02.008

NEERI (2010) Air Quality Assessment, Emission Inventory and Source Apportionment Studies: Mumbai. Natl. Environ. Eng. Res. Inst. CPCB, New Delhi, India

NRC (1999) Ozone-forming potential of reformulated gasoline, National Research Council. National Academies Press. 10.17226/9461

Saha J, Chouhan P (2020) Lockdown and unlock for COVID-19 and its impact on residential mobility in India: an analysis of the COVID-19 Community Mobility Reports, 2020. Int J Infect Dis 104:382-389. https://doi.org/10.1016/j.ijid.2020.11.187
Sarfraz M, Shehzad K, Shah SGM (2020) The impact of COVID-19 as a necessary evil on air pollution in India during the lockdown. Environ Pollut 266:115080. https://doi.org/10.1016/j.envpol.2020. 115080

Sharma S, Saraf MR (2018) Source apportionment of PM2.5 \& PM10 concentrations of Delhi NCR for identification of major sources, TERI and ARAI

Sharma S, Zhang M, Anshika Gao J, Zhang H, Kota SH (2020) Effect of restricted emissions during COVID-19 on air quality in India. Sci Total Environ 728:138878. https://doi.org/10.1016/j.scitotenv.2020. 138878

Singh RP, Chauhan A (2020) Impact of lockdown on air quality in India during COVID-19 pandemic. Air Qual Atmos Health 13:921-928. https://doi.org/10.1007/s11869-020-00863-1

Tasić V, Kovačević R, Milošević N (2013) Investigating the impacts of winds on SO2 concentrations in Bor, Serbia. J Sustain Dev Energy Water Environ Syst 1:141-151. https://doi.org/10.13044/j.sdewes. 2013.01.0010

World Health Organisation (2020) Coronavirus Disease (COVID-19) Situation Update Report - 18. https://www.https://cdn.who.int/ media/docs/default-source/wrindia/situation-report/india-situationreport-18.pdf?sfvrsn=7c00a3f_2. Accessed 30 Jun 2020 